\title{
Effect of duration of the pause single-phase auto-reclosing on electro-power transmission capacitance
}

\author{
Tatyana Krasil'nikova ${ }^{1}$, and Saiyod Jononaev ${ }^{{ }^{*}}$ \\ ${ }^{1}$ Novosibirsk State Technical University, 630073, Novosibirsk, Russian Federation
}

\begin{abstract}
This paper discusses the problem associated with accidents in the aerial line (AL) ultra-high voltage (UHV) due to its big length. In lines with a voltage of $500-1150 \mathrm{kV}$ the overwhelming proportion of trips (98\%) is caused by single-phase short circuit (SPSC). A substantial portion (70\%) single-phase short circuits is erratic arc accidents which can be successfully eliminated in a high-speed auto-reclosing (HSAR) or single-phase auto-reclosing (SPAR). Success single-phase auto-reclosing (SPAR) at liquidation by single-phase short circuit (SPSC), on the one hand, is determined by the characteristics of the secondary arc current, and on the other hand the effectiveness of ways to reduce secondary arc current and recovery voltage development. The minimum dead time, at a HSAR it is usually taken as $0.5 \mathrm{~s}$., at single-phase autoreclosing (SPAR) it depends on the current value of the arc support is in the range of 0.5-3.0 s. The article shows high efficiency of use single-phase auto reclosing (SPAR) at liquidation SPSC in a single-chain AL voltage of $500 \mathrm{kV}$, the dependence of the bandwidth of transmission in maintaining the dynamic stability from the length of the pause SPAR.
\end{abstract}

\section{Introduction}

The prevailing type of accidents in the aerial line (AL) of ultrahigh voltage (UHV) are single-phase short circuits (SPSC), the proportion of which exceeds 98\% [1-4]. At the same time, a significant part of the SPSC represents unstable arc faults, which can be successfully eliminated in the cycle of automatic high-speed reclosing (AHSR) or single-phase automatic reclosing (SPAR).

As a design scheme we can use the classic scheme, representing the station, working through the line on the tires of infinite capacity (Fig. 1).

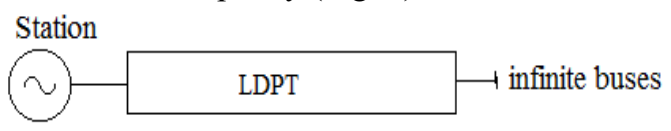

Fig. 1. The calculation scheme

If the minimum no-current pause at AHSR is usually taken of the order of $0.5 \mathrm{sec}$, in the case SPAR it depends on the current value of the arc support is in the range of 0.5-3.0 sec.

It is of interest to analyse the nature of dynamic transitions when using AHSR and SPAR of different duration and to assess the level of bandwidth long distance power transmission (LDPT) UHV by the condition of dynamic stability. Features of the dynamic transition at the estimated failure can be traced with the help of angular characteristics of a normal mode, mode, SHSC, AR (AHSR or SPAR) and post-accident [5].

$$
P_{v}(\delta)=\operatorname{Re}\left(\bar{Y}_{11 v} E_{v}^{2}-\bar{Y}_{12 v} E_{v} U e^{j \cdot \delta}\right)
$$

where $\bar{Y}_{11 v}, \bar{Y}_{12 v}$ - is conjugate values of self and mutual conductances of the circuits for the $\mathrm{v}$ - th mode; $E_{V}$ - electromotive intensity of the station in the v - th mode; $U$ - voltage on the infinite bus.

In the analysis of dynamic stability of SHSC is modeled in the scheme of direct sequence shunt composed of a resistance of zero and negative sequence relative to the injury site, which usually races was a matter of the beginning of the line. It is useful to note that the ratio of the maxima of the angular characteristics in the SHSC in normal mode weakly depend on the circuit parameters, namely the length of the line and the resistance of the starting system (Fig. 2). Therefore, when lengths of over $200 \mathrm{~km}$ can be taken

$$
P_{S H S C}(\delta)=K_{\text {SHSC }} \cdot P_{\text {норм }}(\delta)
$$

where $K_{S H S C}-$ is a coefficient varying within narrow limits, the value of which with reasonable accuracy can adopted $K_{\text {SHSC }}=0.64$.

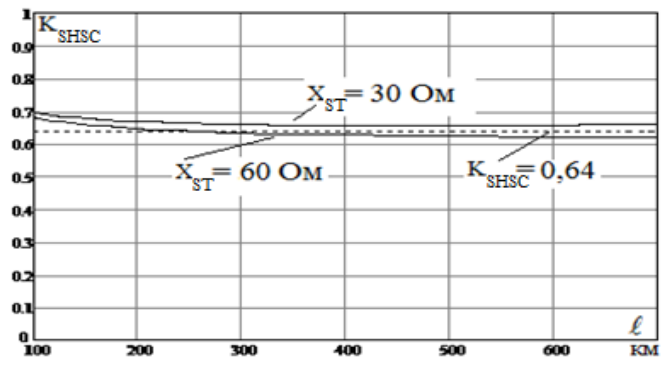

Fig. 2. The ratio of the maxima of the angular characteristics at SHSC in the normal mode depending on circuit parameters 
As in the case of the SHSC, the ratio of the maxima of the angular characteristics in the pause SPAR in the normal regime depends weakly on the parameters of the circuit (Fig. 3).

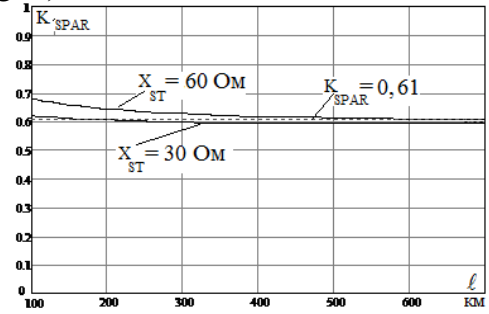

Fig. 3. The ratio of the maxima of the angular characteristics in SPAR in the normal mode depending on circuit parameters

Therefore, as in the case of the SHSC, it is possible to take

$$
P_{S P A R}(\delta)=K_{S P A R} \cdot P_{\text {нори }}(\delta)
$$

where $K_{S P A R}-$ is a coefficient varying within a very narrow range, the value of which may be adopted $K_{S P A R}=0.61$.

Angular characteristics allow it to perform the dynamic nature of the transition, using the method of squares. To determine the angle change of the generators of the power plant in time requires the solution of the equations of motion [6]

$$
\frac{d^{2} \delta}{d t^{2}}=\frac{18000}{T_{j} \cdot S_{n c}}\left[P_{T}(t)-P_{e p g}(\delta, t)\right]
$$

where $T_{j}$ - a constant of inertia of the station; $S_{n c}-$ is the nominal capacity of the plant; $P_{T P}(t)-$ shaft power turbines, which generally varies in the dynamic process of transition, for example, by the discharge pulse of the turbines or the power runs out; $P_{e p g}(\delta, t) \quad-$ electromagnetic shaft power of the generators.

Compare the efficiency AHSR and SPAR with the elimination of SHSC in single-circuit overhead line 500 $\mathrm{kV}$. Analysis will hold in relation to the scheme in which when transmitting $1000 \mathrm{MW}$ the requirements for static stability (the safety factor is 0.25 ).

\section{The use of AHSR}

As analysis shows, in the case of transfer of such power dynamic stability is violated, i.e. the limiting factor for the capacity of the power transmission (PT) is the dynamics. Thus, by the condition of the dynamics, a reduction in the maximum transmitted power in the normal mode is required, i.e. throughput capacity of the $\mathrm{PT}$, so that when the accident is eliminated, dynamic stability is maintained. The solution of the equation of motion of the generator (4) with the duration of the SHSC $0.1 \mathrm{sec}$ and the 0.5 -second AHSR pause showed that the dynamic stability is retained only when power transmission is no more than 420 MW (Fig. 4). The deviation of the angle to the end of the AHSR pause when the transition to the angular characteristic of the post-emergency mode occurs is $\delta_{\text {AHSR }}=98^{\circ}$.

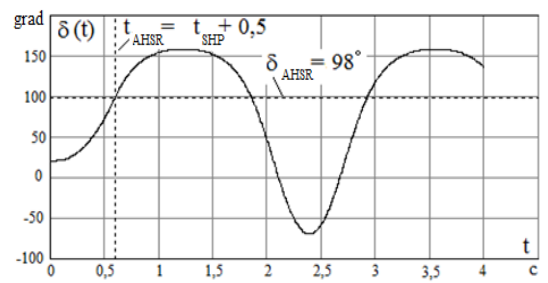

Fig. 4. The angle change in the process of dynamic transition

The condition of preservation of dynamic stability is illustrated using angular characteristics in Fig. 5, which shows the equality of the sites of acceleration and braking.

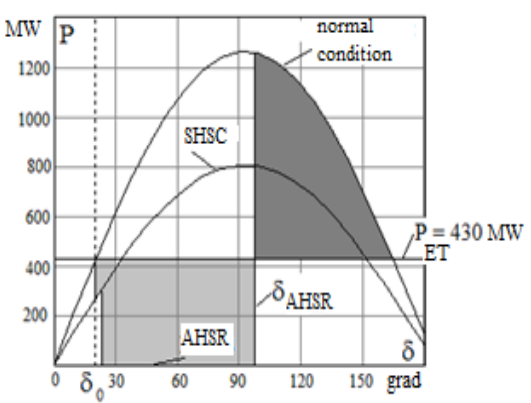

Fig. 5. Angular characteristics of acceleration and deceleration when using AHSR

\section{The use of SPAR}

The solution of equation (4) with the duration of the SHSC $0.1 \mathrm{sec}$ and the pause of the SPAR 0.5, 1.0 and $2.0 \mathrm{sec}$ is illustrated in Fig. 6.
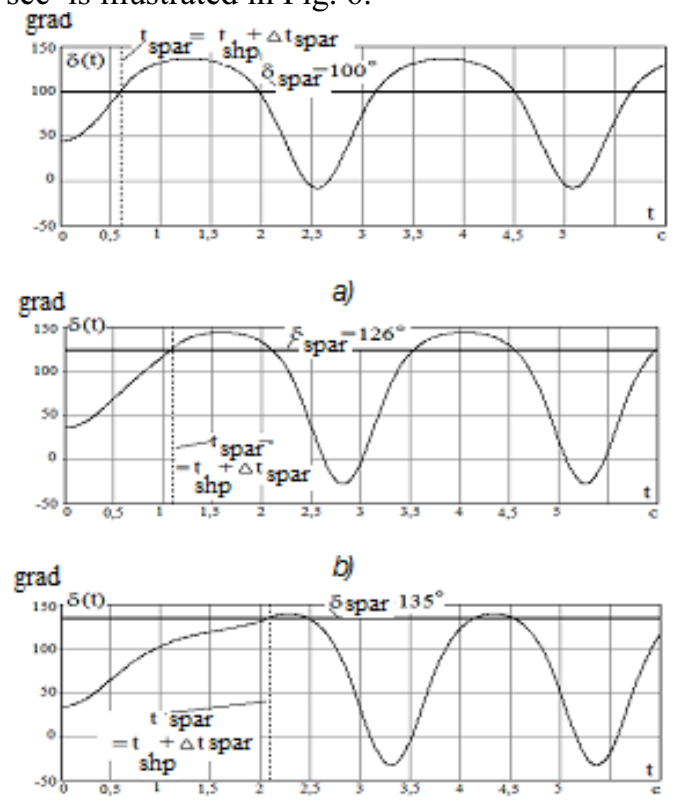

v)

Fig. 6. The angle change in the process of dynamic transition a $-\square t_{S P A R}=0.5 \mathrm{sec} ; \mathrm{b}-\square t_{S P A R}=1.0 \mathrm{sec} ; \mathrm{v}-\square t_{S P A R}=2.0 \mathrm{sec}$ 
Table 1. The characteristic parameters of the dynamic transition at SPAR

\begin{tabular}{|c|c|c|}
\hline $\begin{array}{c}\text { Pause duration } \\
\text { SPAR, sec }\end{array}$ & $\begin{array}{c}\text { The deviation of } \\
\text { transmission } \\
\text { capacity, MW }\end{array}$ & $\begin{array}{c}\text { the angle to the } \\
\text { end of the pause } \\
\text { SPAR, hail }\end{array}$ \\
\hline 0.5 & 863 & 100 \\
\hline 1.0 & 724 & 126 \\
\hline 2.0 & 679 & 135 \\
\hline
\end{tabular}

The conditions of preservation of dynamic stability under various pauses SPAR are illustrated using angular characteristics in Fig. 7, which shows the equality of the respective sites of acceleration and braking.

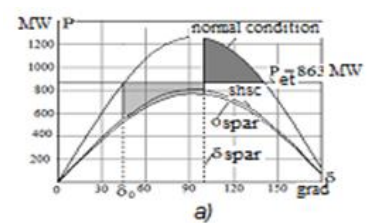

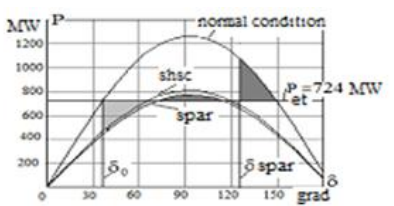

b)

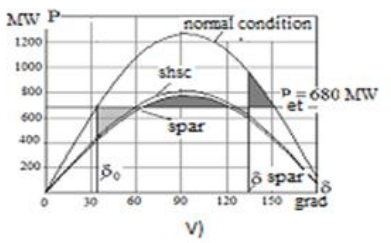

Fig. 7. Angle characteristics and areas of acceleration and braking when using the SPAR: $\mathrm{a}-\square t_{S P A R}=0.5 \mathrm{sec} ; \mathrm{b}-$ $\square t_{S P A R}=1.0 \mathrm{sec} ; \mathrm{v}-\square t_{S P A R}=2.0 \mathrm{sec}$

Using the angular characteristics in Fig. 8, we find the transmission capacity of the power transmission, in which the duration of the SPAR pause by the condition of the dynamics can be arbitrarily large.

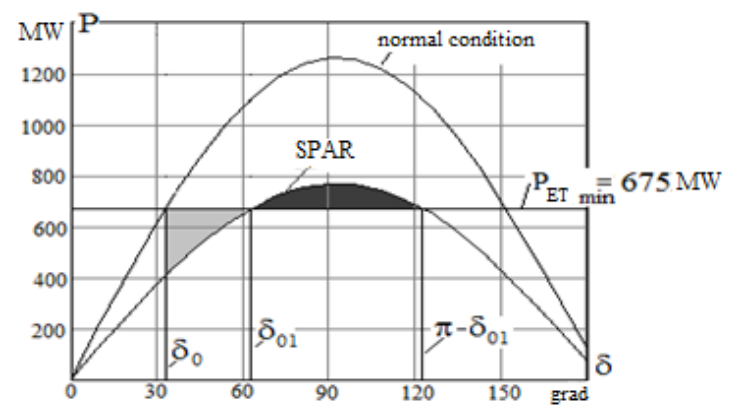

Fig. 8. The definition of transmission capacitance with unlimited pause SPAR

This capacity is found from the condition of equality of the acceleration and deceleration areas in the SPAR mode (the angular characteristic for SHSC differs little from the angular characteristic for the SPAR and therefore they can be assumed to be coincident)

$$
\int_{\delta_{o}}^{\pi-\delta_{o 1}}\left(P_{\mathrm{ET} \min }-P_{\mathrm{SPAR} \max } \cdot \sin \delta\right) d \delta=0 .
$$

After the transformations, we obtain the following equation for determining the minimum throughput that can be achieved with an unlimited pause of the SPAR

$$
\begin{aligned}
& P_{e t \text { min }}\left(\pi-\arcsin \frac{P_{e t \text { min }}}{P_{\mathrm{n} \text { max }}}-\arcsin \frac{P_{\mathrm{ET} \min }}{P_{\mathrm{SPAR} \max }}\right)- \\
& -\frac{P_{\mathrm{SPAR} \max }}{P_{\mathrm{n} \text { max }}} \sqrt{P_{H \text { max }}^{2}-P_{e t \text { min }}^{2}}- \\
& -\sqrt{P_{\mathrm{SPAR} \max }^{2}-P_{e t \text { min }}^{2}}=0
\end{aligned}
$$

The solution of this equation with the received data is given by $P_{\text {ET min }}=675 \mathrm{MW}$.

Now, the dependence of transmission capacity on the condition of maintaining dynamic stability on the duration of the SPAR pause can be constructed (Fig. 9). In Fig. 9 also shows the size of the transmission capacity of the transmission by the condition of the dynamics when using the AHSR with a pause duration of $0.5 \mathrm{sec}$.

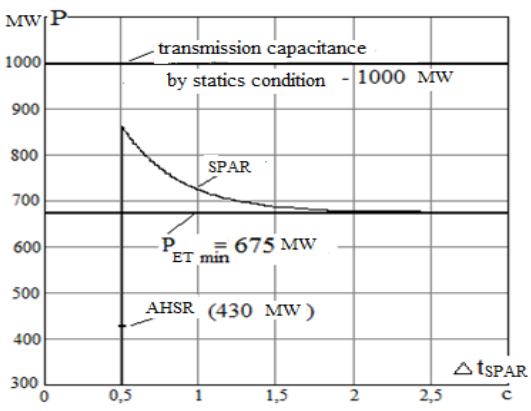

Fig. 9. The dependence of the transmission capacity of the transmission in condition for the dynamic stability from the length of the pause SPAR

On the basis of the above algorithm, we analyze the conditions for the extinction of the secondary arc during the pause of the SPAR in the projected AL of the Kyrgyz Republic-Republic of Tajikistan with a voltage of 500 $\mathrm{kV}$ and a length of $477 \mathrm{~km}$. Lines of this length, as a rule, are equipped with three reactors, which provides a degree of compensation of the charging power of $100 \%$ (Figure 10).

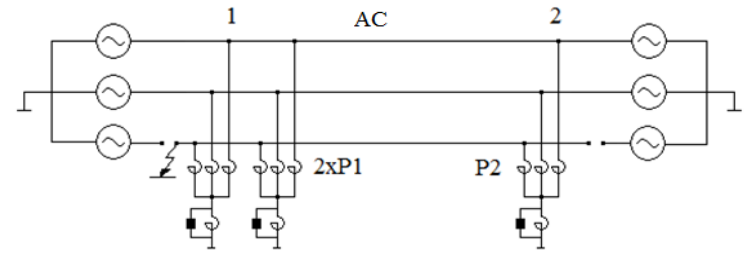

Fig. 10. Scheme of long power line with different number of reactors at the ends of the line

We will focus on the necessary conditions to ensure a successful SPAR. The duration of successful SPAR is projected in the range of $0.5-1.0$ seconds, if the secondary arc current (SAC) will satisfy the condition

$$
I_{\partial} \leq 15-46 A_{\text {ampli }}
$$


The second circumstance to consider is the creation of acceptable conditions of work overshoot suppression (OS) pause SPAR. Recovering voltage (RV) to pause SPAR in the place of installation of the arrester should be limited to $U_{R V} \leq U_{\text {cons.bea, where }}$ $U_{\text {cons.bea }}=230 \kappa B$ for overhead lines with a voltage of $500 \mathrm{kV}$.

In Fig. 11 shows the distribution of RV in pause SPAR for different phases of the resistance of the neutral reactor, and Fig. 12 the dependence of RV at the end of the line from the angular shift $\delta$ when SPAR in phases a, $\mathrm{b}$, $\mathrm{c}$ in the real transposition. In the case of actual transposition of RV depends on which phase is SPAR.

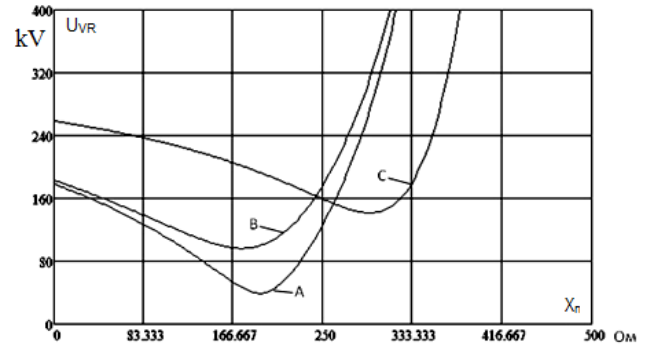

Fig. 11. The distribution of RV in the phases of $A C$ in pause SPAR in real transposition

As we can see from figure 11, the circuit is resonant, and the voltage level at the critical phase exceeds the permissible increasing the voltage on the OS located at the ends of the line.

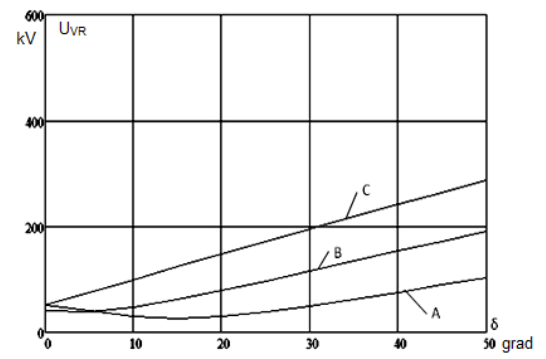

Fig. 12. The dependence of RV on phases at the end of the line from the angular shift between the voltage in a pause SPAR in real transposition

A possible solution to the problem of successful SPAR is to install in series with the shunt reactor (SHR) at the end of the line in the critical phase from the neutral conclusions of the capacitor bank (CB), shunted in normal operation the switch (Fig. 13).

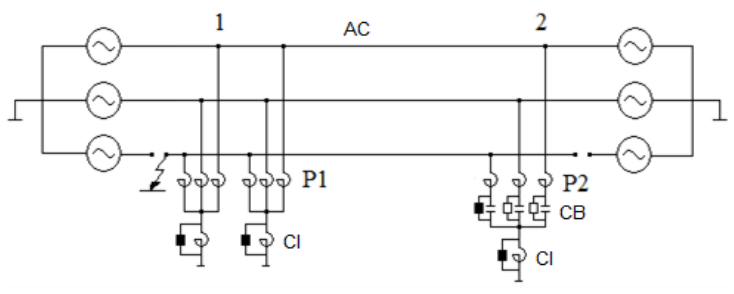

Fig. 13. Device to improve the efficiency SPAR CB in all phases
The calculation shows that the maximum $\mathrm{SAC}$ is estimated by the value $I_{\text {arc }}=35 A_{\text {ampli }}$, and the corresponding pause duration SPAR - $0.8 \mathrm{sec}$.

\section{Conclusion}

The using SPAR compared AHSR allows to increase the throughput of long-range transmission condition of dynamic stability is $1.5-2.0$ times. The greatest effect is the use of SPAR if the pause duration SPAR is in the range $0.5-1.0$, which requires limiting the secondary current to arc (30-45) A (peak value). If you pause more (1.5 to 2.0) sec with its duration has no significant effect on the bandwidth condition of the dynamics, and in this case, the pause duration is determined only by the condition of quenching secondary arc current (SAC).

When calculating $\mathrm{RV}$ in the end of the line with a short-circuit on phase "a" resonance is not observed, therefore no need to connect the capacitor banks to this phase. When a short-circuit on phases "b" and "c" require the installation of capacitor banks.

\section{References}

1. A.S. Zelichenko, B.I. Smirnov Proektirovanie mekhanicheskoi chasti vozdushnykh linii sverkhvysokogo napriazheniia [The planning of mechanical part of overhead lines of extra high voltage]. (Moscow, Energoizdat Publ., 1981. 336 p).

2. I.G. Barg, V.I. Edel'man Vozdushnye linii elektroperedachi: Voprosy ekspluatatsii $i$ nadezhnosti [The overhead transmission lines: Issues of operation and reliability]. (Moscow, Energoatomizdat Publ., 1985. $248 \mathrm{p})$.

3. N.N. Beliakov, V.S. Rashkes, M.L. Levinshtein, M.I. Khoroshev Perspektivy primeneniia OAPV $v$ elektroperedache $1150 \mathrm{kV}$ [The prospects of application of the Single-Phase Auto-Reclosing in power transmission $1150 \mathrm{kV}]$. Elektroperedachi $1150 \mathrm{kV}[1150$ kV transmission]. (Moscow, Energoatomizdat Publ., 1992, bk. 1, pp. 129-158).

4. T.G. Krasil'nikova, S.G. Dzhononaev Sbornik nauchnykh trudov Novosibirskogo gosudarstvennogo tekhnicheskogo universiteta, no. 2 (84), pp. 116-130. (2016).

5. Iu.P. Ryzhov, ed. Rezhimy dal'nikh elektroperedach $v$ primerakh [The modes of long-distance transmission in the examples]. (Moscow, MPEI publ., 1994. 88 p).

6. V.A. Venikov Perekhodnye elektromekhanicheskie protsessy $v$ elektricheskikh sistemakh [The transient Electromechanical processes in electrical systems]. (Moscow, Vysshaya shkola Publ., 1985. 536 p). 